\title{
A Rare Cause of Massive Hepatic Compression: Thoracic Triton Tumor
}

Ikram Chaudhry*, Ahsan Cheema, Hadi Mutairi, Shoukat Bojal, A Balhareth, Samir Amr and MS Al Qahtani Department of Thoracic surgery, Pathology and Hepatobiliary Surgery, King Fahad Specialist Hospital, Saudi Arabia

Submission: June 26, 2018; Published: July 05, 2018

*Corresponding author: Ikram ul haq Chaudhry, Department of Thoracic Surgery, Pathology and Hepatobiliary Surgery, King Fahad Specialist

Hospital, Dammam, Saudi Arabia, Email: drihc007@gmail.com

\section{Abstract}

A 30 years old male presented with dry cough, right hypochondrial pain, tiredness loss of weight and appetite over the last six months. On clinical examination there was palpable non tender mass in right hypochondrium, no jaundice or lymphadenopathy. Computed tomographic scan of chest and abdomen revealed a large mass originating in the lower chest wall and compressing the liver. True cut biopsy showed Malignant Peripheral Nerve Sheath Tumor (MPNST).

Introduction
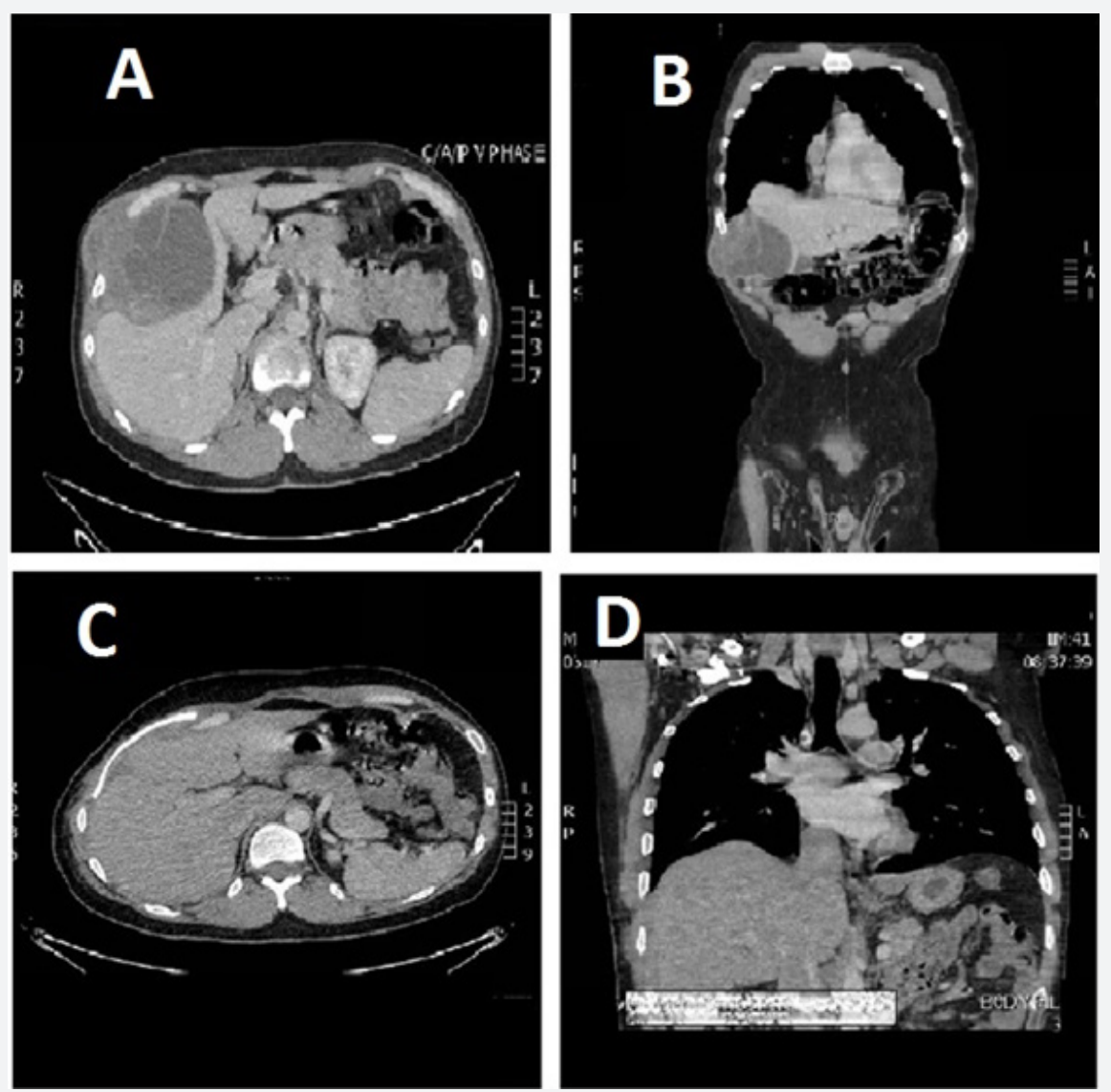

Figure 1: (A\&B) CT scan of chest and abdomen showing a large mass compressing the liver. (C\& D) post-operative CT scan showing the liver decompressed (regained its normal shape). 
Malignant triton tumor is exceedingly rare subset of MPNST which displays rhabdomyosarcomatous differentiation. Although Mason described this first time in 1938 [1] but the actual term triton was introduced by Woodruff in 1973 based on experimental work of Locatelli who observed a growth of supernumerary limb when he transplanted the sciatic nerve on the dorsal surface of triton salamander [2].

Case
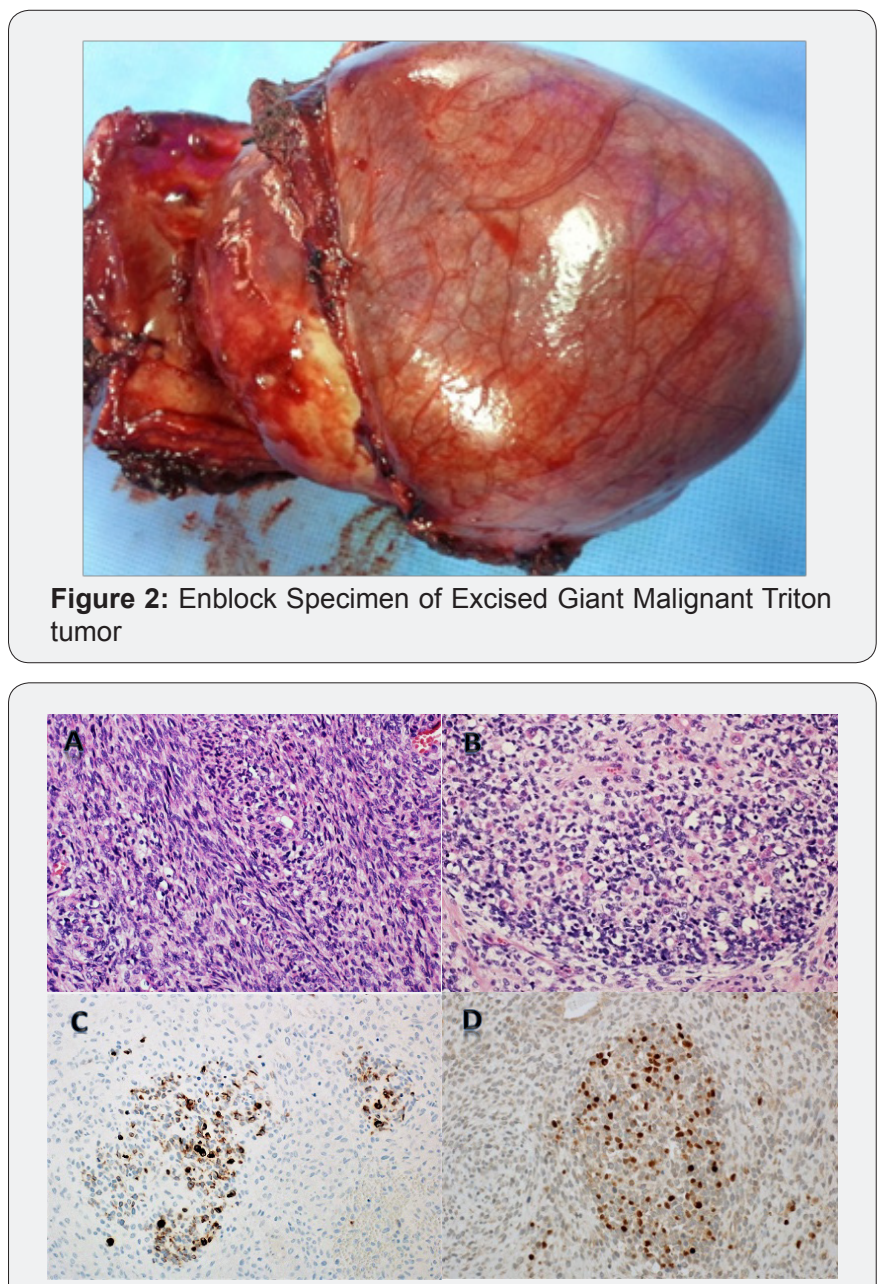

Figure 3: Histopathology and immunohistochemistry slides(A) Malignant peripheral nerve sheath tumor with proliferating malignant spindle tumor cells (B) Higher magnification of a nodule featuring several Rhabdomyoblasts with eosinophilic cytoplasm (H\&Ex400). (C) Immunostains for desmin show several positive cytoplasmic staining of Rhabdomyoblasts.(D). Immunostains for myogenin show positive nuclear staining of Rhabdomyoblasts.

A man aged 32 years, nonsmoker presented with right hypochondrial pain gradually worsening over the last six months. There was no history of cough, weight loss or appetite. On clinical examination there was no cyanosis, jaundice or lymphadenopathy, there was palpable fixed, nontender mass in right hypochondrium.

Ultrasound of abdomen showed a large mass compressing the liver. Chest X-ray showed shadow at right lower chest. CT scan of chest revealed a large $15 \times 10 \mathrm{~cm}$ mass compressing the liver (Figure 1). Basic blood investigations, white cell count, hemoglobin and renal panels were normal but liver enzymes were deranged, Alanine Transaminase (ALT) 45u/lit, Aspartate Transaminase (AST) 24u/LIT, Alkaline Phosphatase 350u/lit. A true cut biopsy histopathology showed malignant nerve sheath tumor and further immunohistochemical stain for desmin show several positive cytoplasmic staining of Rhabdomyoblasts (Figure 2). Further Immunostains for myogenin show positive nuclear staining of Rhabdomyoblasts which are specific diagnostic criteria for malignant triton tumor. The case was discussed in multidisciplinary meeting and recommendation was to proceed for surgery.

Thoracoabdominal incision (extending from right 8th intercostal space to subcostal abdominal area) was given and we found a large tumor arising from $10^{\text {th }}$ intercostal nerve extending in to abdomen massively compressing the liver fig without any liver parenchymal infiltration. Tumor was resected enblock with four ribs and overlying abdominal muscles and part of diaphragm (Figure 2). The abdominal wall defect was repaired with mesh and chest wall defect was reconstructed with methyl methacrylate marlex mesh. Patient was extubated on table and his post-operative course was uneventful. Patient was followed up in outpatient with serial CT scan of chest and abdomen and he remained disease free for one year. Later he developed multiple pulmonary nodules and biopsy confirmed recurrence of malignant triton tumor and he was referred to palliative medicine for further care (Figure 3).

\section{Discussion}

The tumors arising from a peripheral nerve or pre-existing nerve sheath tumor such as neurofibroma are all classified by WHO as MPNST [3]. The MPNST originate from Schwann cells or pleuripotent cells of neural crest and accounts for $5 \%$ of all soft tissue sarcoma. The incidence of MPNST is $0.001 \%$ in general population and $0.16 \%$ in patients with neurofibromatosis type 1 NF1 [4]. Malignant Triton Tumor (MTT) is extremely rare subset which accounts for $<10 \%$ of all MPNST, it commonly occurs in young population and $50-70 \%$ among those are with NF1 disease $[5,6]$. Sporadic cases $20-30 \%$ has been reported in older age group without NF1. These patients are often asymptomatic for long time unless the tumor enlarges rapidly to cause mass effect or invasion of surrounding structures.

CT and positron emission tomography scans are the imaging tools for the initial diagnosis. PET scan is useful to reveal the distant metastasis in addition to the detail of primary tumor. The final diagnosis is based on the histological and immunohistochemical findings [7]. Triton tumor has a very poor prognosis and recurrence rate is very high after surgery therefore radical surgical resection with wider clear margins is the mainstay of treatment. However due to its large size complete removal is not possible in the anterior mediastinum and patient survival is poor. Whatever is the location of tumor five year survival rate is $12-14 \%$. Although the role of radiation and chemotherapy is not well-defined but still the standard treatment for MTT is radical excision with wide tumor free margins followed by high dose 
radiation therapy for better survival. There is large case series reported about the poor prognosis associated with MTT.

McConnell \& Giacomantonio [8] reported after reviewing the 124 cases of malignant triton tumor that the overall five years survival rate of $14 \%$ and median survival of 13 months and local recurrence rate was $50 \%$ [8]. MTT is rarely reported in mediastinum, lung and heart $(<10 \%)$ [9]. We report a rare case of thoracic malignant triton tumor arising from intercostal nerve presented as right hypochondrial pain and massive liver compression. Initial diagnosis was space occupying liver lesion. Operative finding showed a giant malignant triton tumor originating from intercostal nerve and protruding into the abdomen compressing the liver. Tumor was excised radically with wider tumor free margins and chest wall was reconstructed. Patient remained disease free for one year after that he had multiple metastases in the lung and was referred to palliative care. In our opinion despite of radical resection with negative margins unexplained biological behavior merits further research to have better survival.

\section{References}

1. John A Howington, Matthew G Blum, Chang AC, Balekian AA, Murthy SC (2013) Treatment of Stage I and II Non-small Cell Lung Cancer: Diagnosis and Management of Lung Cancer. Chest 143(5_Suppl): e278S-e313S
2. Cheng Shen, Guowei Che (2014) Clinicopathological analysis of pulmonary mucoepidermoid carcinoma. World J Surg Oncol 12: 33.

3. Miller DL, Allen MS (1993) Rare pulmonary neoplasms. Mayo Clin Proc 68(5): 492-498.

4. Kim TS, Lee KS, Han J, Im JG, Seo JB, et al. (1999) Mucoepidermoid carcinoma of the tracheobronchial tree: radiographic and CT findings in 12 patients. Radiology 212(3): 643-648.

5. Ishizumi T, Tateishi U, Watanabe S, Maeda T, Arai Y (2007) F-18 FDG PET/CT imaging of low-grade mucoepidermoid carcinoma of the bronchus. Ann Nucl Med 21(5): 299-302.

6. Yousem SA, Hochholzer L (1987) Mucoepidermoid tumors of the lung. Cancer 60: 1346-1352.

7. Lukomsky G, Tetarchenko V (1979) Bronchology. St Louis, Mo: Elsevier Mosby 287-305.

8. Qian X, Sun Z, Pan W, Ye Q, Tang J, et al. (2013) Childhood bronchial mucoepidermoid tumors: A case report and literature review. Oncol Lett 6(5): 1409-1412.

9. Kim MJ, Shin HC, Shin KC, Ro JY (2013) Best immunohistochemical panel in distinguishing adenocarcinoma from squamous cell carcinoma of lung: tissue microarray assay in resected lung cancer specimens. Ann Diagn Pathol 17(1): 85-90.

10. Kuzucuoglu M, Karamustafaoglu YA, Cicin, Yoruk Y (2014) A rarely seen mucoepidermoid carcinoma of the left main bronchus. J Can Res Ther 10(2): 384-386.

\section{Your next submission with Juniper Publishers} will reach you the below assets

- Quality Editorial service

- Swift Peer Review

- Reprints availability

- E-prints Service

- Manuscript Podcast for convenient understanding

- Global attainment for your research

- Manuscript accessibility in different formats

( Pdf, E-pub, Full Text, Audio)

- Unceasing customer service

Track the below URL for one-step submission https://juniperpublishers.com/online-submission.php 